\title{
Do young adults with childhood asthma avoid occupational exposures at first hire?
}

\author{
O. Dumas*,\#, L.A.M. Smit ${ }^{\dagger}$, I. Pin ${ }^{+, \S, f}$, H. Kromhout ${ }^{\uparrow}$, V. Siroux ${ }^{+, \S}$, R. Nadif*,\#, \\ R. Vermeulen", D. Heederik", M. Hery**, D. Choudat"\#, F. Kauffmann*,\# and \\ N. Le Moual*,\#, on behalf of the Epidemiological Study on the Genetics and \\ Environment of Asthma (EGEA)
}

ABSTRACT: Information on the healthy worker hire effect in relation to asthma is scant. We aimed to assess whether and how childhood asthma-related characteristics (before hire) relate to occupational exposures at first hire.

Analyses were conducted in 298 children examined at the first survey of the Epidemiological Study on the Genetics and Environment of Asthma (1991-1995), who reported a training period or a job at follow-up in 2003-2007 (aged 17-29 yrs; 53\% males). Exposure likelihood to dust, gases and/or fumes in their first occupation was estimated by the ALOHA job exposure matrix. Asthma before the first occupation and two asthma classifications for severity (Global Initiative for Asthma 2002 guidelines) and symptoms were defined by questionnaire.

In their first job, $47 \%$ of subjects were exposed. After adjustment (age, sex and education), prehire onset asthmatics (59\%) were nonsignificantly less likely to be exposed (OR $0.67,95 \% \mathrm{Cl} 0.41-$ 1.11). Associations were stronger when considering those with severe asthma or high symptom score in childhood (OR 0.27 (95\% Cl 0.11-0.63) and OR 0.49 (95\% Cl 0.25-0.99), respectively). The association was observed in those who completed a university degree (OR $0.55,95 \% \mathrm{Cl} 0.29$ 1.04) but not in the others (OR $0.98,95 \% \mathrm{Cl} 0.44-2.22$ ), with consistent results for all asthma characteristics.

Results suggest a healthy worker hire effect in subjects with more severe or more symptomatic asthma in childhood. Education may modulate self-selection.

KEYWORDS: Asthma, healthy worker hire effect, longitudinal study, occupational exposure, selection bias

$\mathbf{R}$ ecent studies have estimated that $10-15 \%$ of adult-onset asthma is attributable to occupational exposure [1, 2]. Workexacerbated asthma, i.e. worsening of a preexisting asthma induced by exposure at the workplace, has been less studied, but might represent $45 \%$ of all work-related asthma cases $[3,4]$. However, associations between occupational exposures and asthma are probably underestimated as a result of the "healthy worker effect" selection phenomenon [5]. New-onset asthma or exacerbation of pre-existing asthma may lead to avoidance of occupational exposures by less healthy workers who may decide to move to a low-exposure or nonexposed job. This so-called healthy worker survivor effect has been suggested in relation to asthma in several studies [5].
The healthy worker hire effect, i.e. an early selection mechanism arising from career choice through the selection at hire of a work environment without hazardous exposures by individuals with a pre-existing asthma, has been less studied. Recently, a study from the European Community Respiratory Health Survey (ECRHS) showed that adults with asthma onset prior to entering the workforce were less likely to report current or previously held jobs involving inhalation exposures [6]. Whether these associations reflect initial ("hire effect") or continuing ("survivor effect") selection processes could not be determined. In a study that evaluated the job that teenagers would like to have in the future, teenagers with respiratory symptoms did not significantly more often indicate a job with no asthma risk than teenagers without respiratory

\section{AFFILIATIONS}

*Inserm, CESP Centre for research in Epidemiology and Population Health, U1018, Respiratory and

Environmental Epidemiology Team, and

\#Université Paris Sud 11, UMRS 1018, F-94807, Villejuif,

+Inserm, U823, Centre de Recherche

Albert Bonniot, La Tronche,

§Université Joseph Fourier and

${ }^{f} \mathrm{CHU}$, Grenoble,

${ }^{* *}$ Institut National de Recherche et de Sécurité, Vandoeuvre-lès-Nancy, and

\#\#Université Paris Descartes,

AP-HP, Paris, France.

"IRAS, Utrecht University, Utrecht, The Netherlands.

"A full list of the EGEA cooperative group members and their affiliations can be found in the

Acknowledgements section.

CORRESPONDENCE

0. Dumas

Respiratory and Environmental Epidemiology

CESP/U 1018 Inserm

16 avenue Paul Vaillant Couturier 94807 Villejuif Cedex

France

E-mail: orianne.dumas@inserm.fr

Received:

April 142010

Accepted after revision:

Aug 242010

First published online:

Sept 302010 
symptoms [7]. The magnitude and the determinants of healthbased self-selection at hire due to asthma remain to be ascertained. In particular, the role of the clinical expression and the history of the disease, and of socioeconomic factors needs to be studied [6].

The longitudinal design of the French Epidemiological Study on the Genetics and Environment of Asthma (EGEA) enabled us to follow subjects from childhood to the beginning of their working life. In the present analysis, we aimed to assess: 1) whether subjects with childhood-onset or pre-hire-onset asthma will avoid occupational exposure in their first job; 2) which clinical characteristics are involved in this self-selection process, with a particular attention to asthma severity, asthma symptoms, and allergic sensitisation and lung function in both asthmatics and nonasthmatics; and 3) whether sociodemographic characteristics, such as sex, education and smoking, modify asthma-based self-selection at hire.

\section{MATERIALS AND METHODS Population}

The present analysis used the longitudinal data from the casecontrol and family-based EGEA study [8]. The present study was conducted in subjects included as children ( $<16$ yrs of age) at baseline (EGEA1, 1991-1995) and who had ever worked at follow-up (EGEA2, 2003-2007). Of the 604 children enrolled at baseline (including asthmatic cases, their first-degree relatives and population-based controls), 547 took part in the follow-up phase. A total of 141 completed only a brief postal questionnaire with no information about occupation (or only for their two most recent jobs). A total of 393 subjects completed a detailed questionnaire comprising complete occupational history (supplementary fig. E1) and among them, 318 had ever worked (i.e. reported at least one occupation). Subjects who had only done short-term part-time or seasonal work irrelevant to a career choice $(n=8)$, or with unclear occupational history $(n=1)$ were excluded. Finally, analyses were performed for 298 subjects, after excluding subjects with missing data for exposure $(n=1)$, education $(n=2)$ or parental asthma $(n=9)$, in order to have a constant number for the "nonasthmatics" reference category.

\section{Asthma characteristics}

Information on asthma and related clinical characteristics at baseline (including allergic rhinitis) were recorded by questionnaire (based on a standardised questionnaire designed for children [9] with further questions from the ECRHS questionnaire for asthma-like symptoms), administered by an interviewer to the parents (usually the mother). Methods used to ascertain asthma and related characteristics have been described previously [8, 10] and details are provided in the online supplementary material.

Subjects with pre-hire-onset asthma, i.e. asthma onset before the first occupation, comprised asthmatics at EGEA1 (asthma onset in childhood, $\mathrm{n}=150$ ), and asthmatics at EGEA2 with age at onset younger than the age at the first occupation (with $\geqslant 1$ yr between asthma onset and first hire, $n=25$; fig. 1 ). To evaluate whether asthma was still present just before hire, asthmatics were classified according to the presence of asthma attacks in the year before the first occupation, using EGEA2 retrospective questions on asthma history: "Have you ever had a period of several years without attacks?"; if the answer to

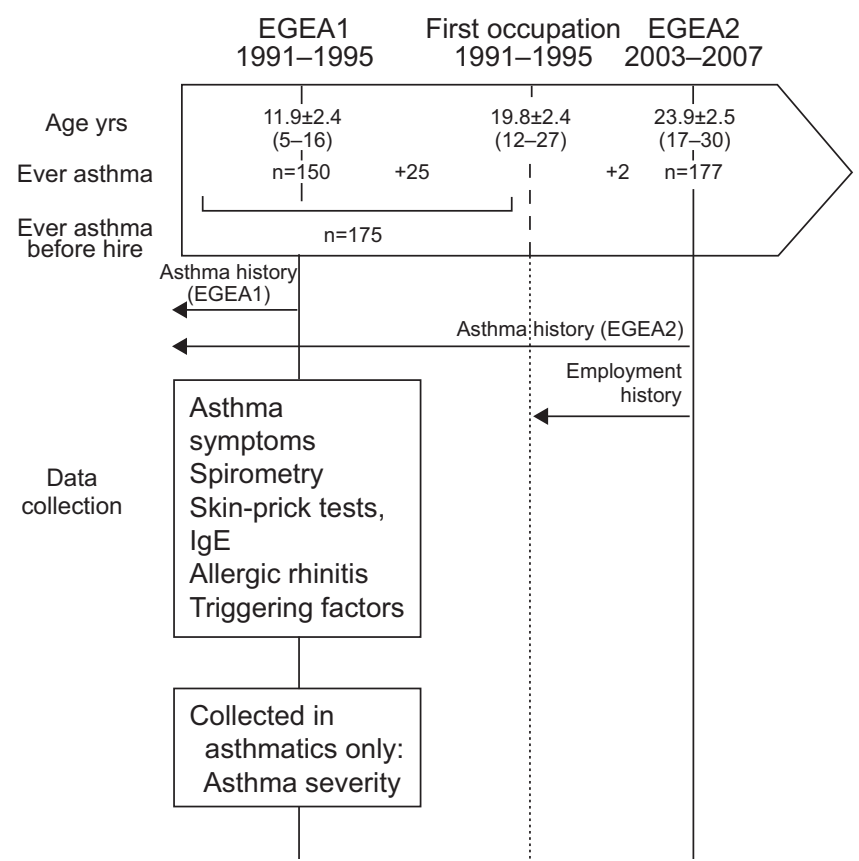

FIGURE 1. Study design. Age data are presented as mean $\pm S D$ (range) EGEA: Epidemiological Study on the Genetics and Environment of Asthma; Ig: immunoglobulin.

this question was yes, "At what age did attacks disappear/ reappear?". Parental asthma was taken into account only if parental asthma onset occurred before the first hire of the child.

To assess asthma severity in childhood (available among the 150 subjects with asthma at baseline; fig. 1), a four-level classification was constructed in close accordance with the principles of the Global Initiative for Asthma (GINA) 2002 guidelines [11], as previously performed in EGEA [12]. The classification was based on clinical characteristics and type of treatment in the past year (see online supplementary material). A score of 1-2 was classified as "mild asthma" and a score of 3-4 as "moderate to severe asthma". Additionally, a five-level asthma symptom score has been constructed for children, adapted from that described for adults by PEKKANEN et al. [13] and SUNYER et al. [14], and already used in the EGEA [15]. Examination at baseline included total serum immunoglobulin (Ig)E, skin-prick tests (SPT) to 11 aeroallergens and lung function tests, including methacholine challenge. Bronchial responsiveness was assessed by the dose-response slope according to CHINN et al. [16], which decreases with hyperresponsiveness.

\section{Occupational exposure}

At follow-up, education level was recorded, and each training period and job performed was precisely recorded (position and industry title, and job task), and subsequently coded according to the International Standard Classification of Occupations (ISCO)-88 four-digit coding system [17] by an experienced coder, as recommended [18]. For the present study, the first occupation, i.e. the first job or the first training period performed, was selected. 
For the main analysis, exposure to dust (biological and mineral), vapours, gases, fumes, pesticides, solvents and metals was assessed using an updated version $(\mathrm{H}$. Kromhout and R. Vermeulen, Utrecht University, Utrecht, The Netherlands) of the ALOHA job-exposure matrix [19, 20], which assigns to each job code a probable exposure category (none, low or high) for each agent. The outcome of interest was "low or high exposure to at least one agent" versus "no exposure". All subjects classified as "exposed" were at least exposed to dust, vapours, gases and/or fumes, except one (exposed to solvents and metals only).

Additional analyses were performed using an asthma-specific job-exposure matrix [18] containing 22 exposure groups classified as high risk agents (moderate or high probability of exposure to high or low molecular weight agents, or a mixed environment) or low risk agents (possible exposure to irritants or antigens). The application of this matrix included an occupational hygiene expert re-evaluation step (D. Heederik, Utrecht University; M. Hery, Institut National de Recherche et de Sécurité, Vandoeuvre-lès-Nancy, France; and N. Le Moual, Inserm, CESP Centre for research in Epidemiology and Population Health, U1018, Respiratory and Environmental Epidemiology Team and Université Paris Sud 11, UMRS 1018, Villejuif, France).

\section{Statistical analysis}

Associations between exposure in the first job (outcome) and asthma before hire or related clinical characteristics (predictors) were evaluated by logistic regression analysis. Analyses were adjusted for sex, age and education level ("university diploma level" refers to completion of $\geqslant 2$ yrs of postsecondary education) at follow-up. Further adjustment for smoking led to similar results (data not shown). Sex, smoking and diploma level have also been tested as potential effect modifiers for the relationship between asthma and exposure by adding interaction terms in multivariate models. The familial structure of the data was taken into account by using the Generalised Estimating Equations approach, which allows the specification of a correlation structure (the correlation between siblings has been assumed constant) in a generalised linear model. The analysis was performed using SAS 9.1 (SAS Institute, Cary, NC, USA).

\section{RESULTS}

Among the 393 subjects who completed the detailed adult questionnaire at follow-up, having ever worked was not associated with any studied clinical characteristic (data not shown). The 298 selected subjects were aged 17-29 yrs at follow-up and 175 (59\%) had asthma before their first job (table 1). There were marked differences according to asthma for childhood symptom score, bronchial hyperresponsiveness (BHR), SPT, IgE and allergic rhinitis (table 1). A total of $36 \%$ of pre-hire-onset asthmatics had a high (4-5 points) symptom score, and $28 \%$ of asthmatics at baseline had moderate to severe asthma. Subjects with pre-hire-onset asthma were significantly more often male, younger at EGEA2 and younger at their first employment than nonasthmatics. The slight difference in diploma level according to asthma $(p=0.11)$ disappeared after adjusting for age $(\mathrm{p}=0.44)$. Among pre-hireonset asthmatics, $21(12 \%)$ subjects declared having received advice regarding job choices related to asthma or respiratory health. This advice were most often (33\%) provided by a physician, and regarded mostly a specific job or exposure (animals, diving, flying, etc.).

The first occupation was a training period for 226 subjects and a job for 72. Beginning with a training period was unrelated to asthma status, exposure, sex and age, but associated with a higher diploma level (65\%) than beginning with a job $(46 \%)$ $(\mathrm{p}=0.003)$.

The $140(47 \%)$ subjects classified as exposed according to the ALOHA job exposure matrix (to dust, gases, fumes, pesticides, solvents and/or metals) were more likely to be male (54\% males exposed versus $39 \%$ females; $p=0.01$ ) and to have a lower education level (38\% exposed in subjects with university diploma level versus $60 \%$ for a lower level; $\mathrm{p}<0.001$ ) and were similar regarding age or smoking status. According to the asthma-specific job exposure matrix, $30 \%$ of subjects were exposed, with consistent results regarding sex, age, diploma level and smoking status.

Subjects with pre-hire-onset asthma were less frequently exposed (ALOHA job exposure matrix; table 2) at the first occupation (45\%) than nonasthmatics before hire (50\%), but the association did not reach significance (adjusted $\mathrm{p}=0.12$ ). Associations were similar in males and females (OR 0.62 (95\% CI $0.31-1.25)$ and OR 0.73 (95\% CI $0.34-1.57)$, respectively), and in smokers and nonsmokers (OR 0.63 (95\% CI 0.301.30) and OR 0.71 (95\% CI 0.36-1.38), respectively). Among pre-hire-onset asthmatics with a high symptom score in childhood, 39\% were exposed (compared with nonasthmatics before hire; $\mathrm{p}=0.12$ ). This association was more pronounced and significant after adjustment (OR 0.49, 95\% CI 0.25-0.99). No difference was observed among asthmatics according to the presence or absence of attacks the year before the first occupation. The analysis of exposures estimated by the asthma-specific job exposure matrix provided similar associations (table 2).

Among asthmatics with moderate-to-severe asthma at baseline (table 3), 27\% were exposed at the first occupation (compared to nonasthmatics before hire; $\mathrm{p}=0.01$ ), resulting in adjusted $\mathrm{OR}$ 0.27 (95\% CI 0.11-0.63) (ALOHA job-exposure matrix) and adjusted OR 0.31 (95\% CI $0.12-0.82)$ (asthma-specific job exposure matrix). In tables 2 and 3, differences between crude and adjusted ORs were mainly explained by adjusting for sex and diploma level.

Pre-hire-onset asthma combined with parental asthma was associated with a lower risk of exposure at the first occupation compared with subjects without asthma and parental asthma (OR 0.48, 95\% CI 0.25-0.89; ALOHA job exposure matrix). Intermediate associations were observed for the effect of parental asthma or asthma alone (OR 0.62 (95\% CI 0.30-1.29) and OR 0.67 (95\% CI 0.33-1.37), respectively). According to the asthma-specific job exposure matrix, no significant association was observed.

In analyses of the specific exposures estimated by both matrices, significant associations were found for most of the specific exposures, and the lowest OR was obtained for exposure to high molecular weight agents (supplementary table E2). 
TABLE 1 Description of the population according to asthma status before hire

\begin{tabular}{|c|c|c|c|c|}
\hline & \multirow[t]{2}{*}{ All } & \multicolumn{2}{|c|}{ Asthma before hire } & \multirow[t]{2}{*}{ p-value } \\
\hline & & No & Yes & \\
\hline Subjects & 298 & 123 & 175 & \\
\hline \multicolumn{5}{|l|}{ Baseline data in childhood at EGEA1 } \\
\hline Males & $158(53.0)$ & $52(42.3)$ & $106(60.6)$ & 0.002 \\
\hline Siblings & $152(51.0)$ & $80(65.0)$ & $72(41.1)$ & \\
\hline Control & $57(19.1)$ & $43(35.0)$ & $14(8.0)$ & \\
\hline Asthmatic at baseline & $150(50.5)$ & & $150(85.7)$ & \\
\hline \multicolumn{5}{|l|}{ Asthma severity ${ }^{\#}$} \\
\hline Mild & $97(37.6)$ & & $97(72.4)$ & \\
\hline Moderate-to-severe & $37(14.4)$ & & $37(27.6)$ & \\
\hline FEV $1 \%$ pred & $98.6 \pm 12.1$ & $99.5 \pm 10.6$ & $98.0 \pm 13.1$ & 0.27 \\
\hline Methacholine challenge & 223 & 103 & 120 & \\
\hline BHR log slope & $5.40 \pm 2.51$ & $6.80 \pm 2.50$ & $4.21 \pm 1.79$ & $<0.001$ \\
\hline \multicolumn{5}{|l|}{ Positive SPT } \\
\hline No & $102(34.9)$ & $73(60.3)$ & $29(17.0)$ & $<0.001$ \\
\hline Yes & $190(65.1)$ & $48(39.7)$ & $142(83.0)$ & \\
\hline $\lg \mathrm{E} \mathrm{IU} \cdot \mathrm{mL}^{-1}$ geometric mean $(95 \% \mathrm{Cl})$ & $149(122-181)$ & $52(39-70)$ & $312(254-382)$ & $<0.001$ \\
\hline Allergic rhinitis & $103(34.7)$ & $12(9.8)$ & $91(52.3)$ & $<0.001$ \\
\hline \multicolumn{5}{|l|}{ Follow-up data at EGEA2 } \\
\hline Age at follow-up yrs & $23.9 \pm 2.5$ & $24.7 \pm 2.5$ & $23.6 \pm 2.4$ & 0.01 \\
\hline Age at the first hire yrs & $19.8 \pm 2.4$ & $20.2 \pm 2.3$ & $19.6 \pm 2.4$ & 0.02 \\
\hline
\end{tabular}

Data are presented as $n, \mathrm{n}(\%)$ or mean $\pm \mathrm{SD}$, unless otherwise stated. EGEA: Epidemiological Study on the Genetics and Environment of Asthma; FEV 1 : forced expiratory volume in $1 \mathrm{~s}$; \% pred: \% predicted; BHR: bronchial hyperresponsiveness; SPT: skin-prick test; Ig: immunoglobulin. * : asthma severity was recorded only among the 150 subjects with asthma at baseline, and was missing for 16 of them.

Associations between exposure at first hire (ALOHA job exposure matrix), and lung function, allergic sensitisation and triggers for respiratory symptoms in childhood were studied in both nonasthmatics and asthmatics (supplementary table E1). In both groups, lung function, BHR and allergic rhinitis were unrelated with exposure. Regarding total IgE and positive SPT, there were no differences according to exposure in those with a history of asthma, whereas among nonasthmatics, exposed subjects tended to a have lower IgE level $(p=0.07)$ and were less likely to have a positive SPT $(p=0.02)$. Subjects with asthma at baseline who reported respiratory symptoms triggered by hay, flowers or pets were significantly less often exposed.

The association between pre-hire-onset asthma and both estimates of exposure was observed in subjects with a university diploma but not in subjects with a lower diploma level: OR 0.55 (95\% CI $0.29-1.04$ ) versus OR 0.98 (95\% CI $0.44-2.22$ ) $(\mathrm{p}$-value for interaction (pinteraction $)=0.19$; ALOHA job exposure matrix); OR 0.47 (95\% CI 0.23-0.97) versus OR 1.38 (95\% CI 0.61-3.11) (pinteraction $=0.02$; asthma-specific job exposure matrix). All associations between exposure and asthma characteristics stratified by diploma level are presented in supplementary table E3.

\section{DISCUSSION}

The present prospective study shows that young adults with an asthma history before starting employment may preferentially choose a first job with low probability of exposure that may be hazardous to respiratory health. This self-selection phenomenon varies according to clinical characteristics of asthmatics: more severe or more symptomatic asthma in childhood was associated with a stronger selection at hire. Allergic sensitisation was also involved in this self-selection 
TABLE 2 Associations between asthma characteristics before hire and exposure at the first occupation

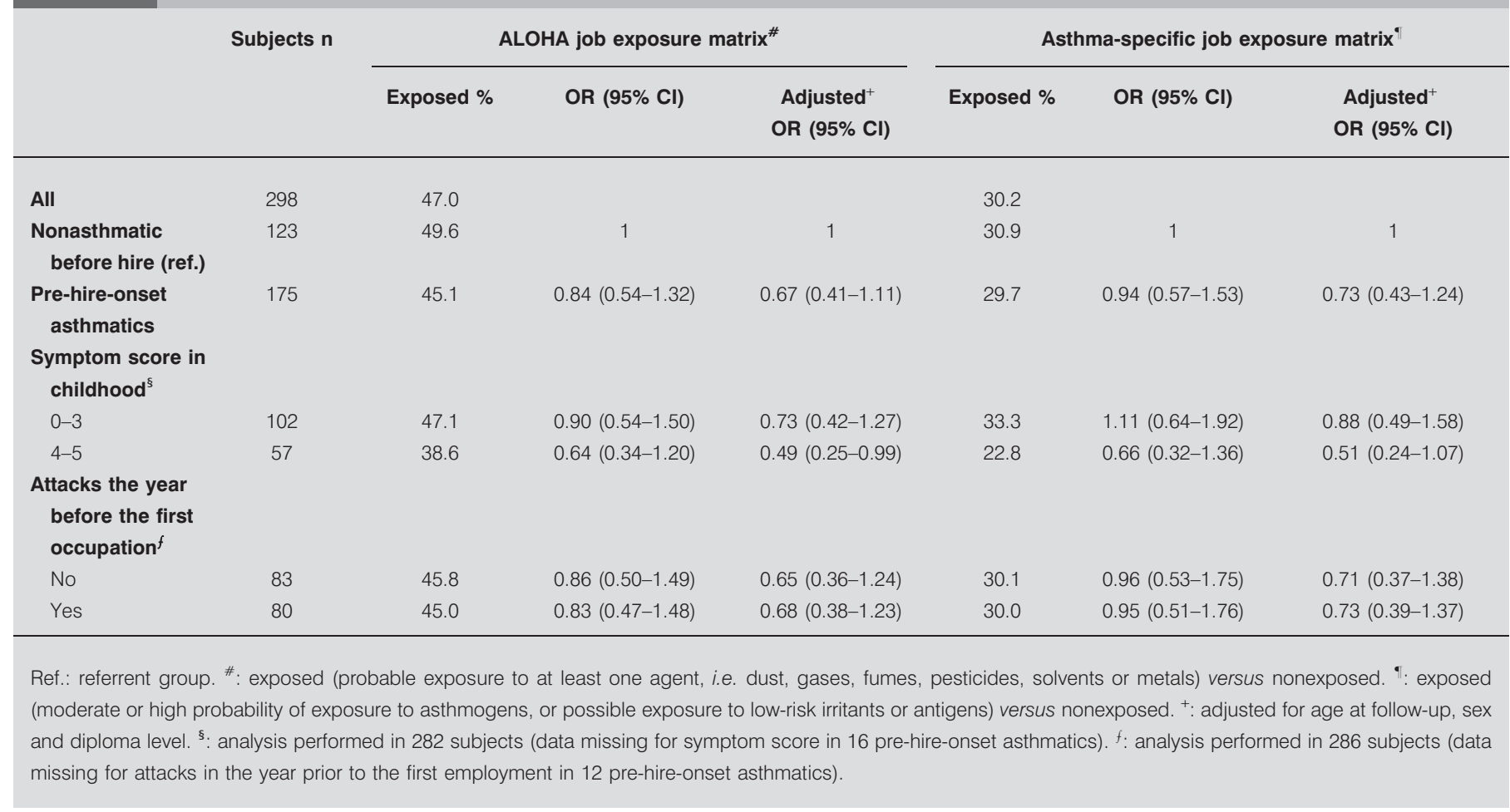

process. Sociodemographic characteristics, such as a higher diploma level, may increase asthma-based self-selection.

This analysis was conducted in subjects followed from childhood to the beginning of their working life. Knowledge of their complete employment history allowed us to study, for the first time, the first training period or job. In France, training periods are, in principle, completed within the framework of studies or vocational education and, thus, represent an involvement in a vocational field and an initial career choice. Two studies have suggested a healthy worker survivor effect in populations of young apprentices, who can be compared to trainees [21, 22]. Training periods must be taken into account to evaluate a potential early selection phenomenon. Exposures were assessed using job exposure matrices rather than self-reported exposure that may be influenced by health status [23]. The ALOHA job exposure matrix estimates a broad range of exposures (dust, gases, fumes, pesticides, solvents and/or metals), which might better correspond to the subject's awareness or perception of occupational risks than a more accurate assessment of asthma-specific agents. Consistent results have been observed with the asthma-specific job exposure matrix, and the analysis of specific exposures suggested a stronger avoidance of occupations with likely exposure to high molecular weight agents, even if the low numbers of subjects in each exposure group limited the interpretation of the results. We studied a young population, describing a recent asthma history (mostly at baseline survey) and employment history (at follow-up); therefore, recall bias is unlikely to have affected our results. However, the population was only of moderate size and, consequently, a lack of power limited some investigations (for instance, taking into account exposure level) and the interpretation of some results.
Our study confirms and extends recent results regarding the healthy worker effect in asthma. Childhood asthma has been reported as a factor influencing the first occupational social class (not blue-collar workers) in a French male cohort [24]. Furthermore, findings from the ECRHS [6] showed that asthma status prior to entering the workforce was related to less exposed jobs, based on retrospective information on asthma and exposures, assessed for the current or most recent job, or a previously held job (if a previous occupational exposure was suspected). Associations observed in ECRHS might reflect both initial selection in career choice ("hire effect") and continuing selection processes ("survivor effect"). Our results are consistent with these findings, as they support an influence of asthma characteristics prior to entering the workforce on the career choice. Furthermore, we have shown that a substantial part of job selection would take place at first hire.

Our results suggest for the first time that childhood health history and socioeconomic parameters modify self-selection at hire. More severe asthma and more symptomatic asthma in childhood were associated with a strong selection at hire. Asthma severity in adults has previously been related to job changes [25]. Our results suggest that the severity and symptoms of the disease experienced in childhood may have an impact on job choice in young adulthood. Despite a good characterisation of asthma in childhood, detailed data on asthma severity and symptoms at the precise moment of hire were not available. In the current analysis, the presence of asthma attacks the year before hire did not increase self-selection, suggesting that job choices may be based on a longer disease history and a larger range of clinical characteristics. 
TABLE 3 Associations between exposure at the first occupation and asthma severity at baseline

Subjects $n$ Exposed \%
48.0

49.6

46.7

51.6

27.0
273

150

97

37
ALOHA job exposure matrix

OR $(95 \% \mathrm{Cl})$
Adjusted $^{+}$

OR $(95 \% \mathrm{Cl})$
Asthma-specific job exposure matrix

Exposed \% OR $(95 \% \mathrm{Cl}) \quad$ Adjusted $^{+}$

OR $(95 \% \mathrm{Cl})$

\begin{tabular}{|c|c|c|c|c|c|c|c|}
\hline All & 273 & 48.0 & & & 30.8 & & \\
\hline $\begin{array}{l}\text { Nonasthmatic } \\
\text { before hire (ref.) }\end{array}$ & 123 & 49.6 & 1 & 1 & 30.9 & 1 & 1 \\
\hline \multicolumn{8}{|c|}{ Asthma severity at baseline $e^{\S}$} \\
\hline Mild & 97 & 51.6 & $1.08(0.63-1.85)$ & $0.88(0.49-1.58)$ & 35.1 & $1.21(0.70-2.10)$ & $0.97(0.53-1.75$ \\
\hline
\end{tabular}

Ref.: referrent group. ${ }^{\#}$ : exposed (probable exposure to at least one agent, i.e. dust, gases, fumes, pesticides, solvents or metals) versus nonexposed. ${ }^{\bullet}$ : exposed (moderate or high probability of exposure to asthmogens, or possible exposure to low-risk irritants or antigens) versus nonexposed. ${ }^{+}$: adjusted for age at follow-up, sex

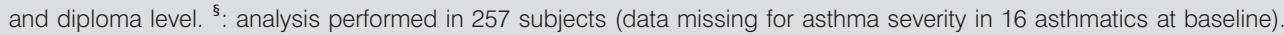

Parental asthma strengthened selection at hire, which was possibly related to parental knowledge or work experience. Genetic factors may also be considered, as they may be associated with specific asthma characteristics that could influence job choice. Familial resemblance in asthma severity has been previously evidenced in the EGEA population [26].

Our results suggest that allergic sensitisation might be involved in health-based selection mechanisms at hire. Positive SPT in childhood predicted less exposure at first occupation, particularly among nonasthmatics (few asthmatics had negative SPT), with consistent results regarding total IgE. Allergic rhinitis did not significantly influence job choice. This result differs partly from a previous study in a cohort of Swedish males born in 1949-1951 [27] reporting job selection in the early period of the working life to be similar in males with allergic rhinitis and those with asthma (diagnosed at military service).

Our results suggest that diploma level might modify the healthy worker hire effect, as only asthmatics with a university diploma avoided jobs with likely exposures (for both exposure estimates), with consistent results for all asthma characteristics studied. Low socioeconomic level has been mentioned previously as a factor leading to less job selection in mortality studies [28], as well as on removal from exposure in red cedar asthmatics [29]. Diploma level reflects both education and socioeconomic conditions, two different aspects that might influence selection at work, through the knowledge of occupational risks [30] and the greater career opportunities. As underlined recently [6], more comprehensive information on socioeconomic conditions are warranted to better understand the various components of the healthy worker effect. In a study that investigated the preferred future job choice in teenagers [7], inconclusive associations were found between respiratory symptoms and the choice of a job without an increased risk for asthma. This study was conducted in vocational trainees, likely with a lower education level, and probably less prone to self-selection, as was shown in our study. We did not find evidence of sex differences in selection (in agreement with the study of OLIVIERI et al. [6]), nor difference between smokers and nonsmokers.

Work-related asthma has an important individual socioeconomic impact [31, 32], that might be reduced by health-based selection in the early period of the working life, but career choices also depend on socioeconomic conditions. Selection might have arisen from a personal choice, an advice from a physician or another person, or from the employer's choice. However, no health-based pre-employment selection policy exists in France. Very few asthmatics declared that they had received advice regarding job choice, and this advice concerned very specific occupational fields. Considering public health surveillance, this study raises the importance of taking into account this selection bias in studies of occupational asthma. Further research is needed to better understand how current estimates of the effect of specific exposures on respiratory health may be affected by the healthy worker effect.

In conclusion, the current study shows in a population of young adults that asthma history plays a role in the choice of the first occupation, and that this choice is further modified by clinical and sociodemographic characteristics. This phenomenon probably leads to an underestimation of associations between occupational exposures and asthma.

\section{SUPPORT STATEMENT}

This study was funded by: the Hospital Programme of Clinical Research (PHRC), Paris, France; National Research Agency, Health Environment, Health-Work Programme (grant ANR-SEST 2005); Merck Sharp \& Dohme (MSD); Isere Committee Against Respiratory Diseases (COMARES); French Agency of Health Safety, Environment and Work (grant AFSSET-EST-09-15); French Ministry of Foreign and European Affairs/Netherland Organization for Scientific Research (NWO) Van Gogh Programme for French-Dutch cooperation; and the University Paris Sud 11 (Paris) ED420 doctoral grant.

\section{STATEMENT OF INTEREST}

A statement of interest for the study itself can be found at www.erj. ersjournals.com/site/misc/statements.xhtml 


\section{ACKNOWLEDGEMENTS}

The members of the EGEA cooperative group are as follows. Coordination: F. Kauffmann (Inserm, CESP Centre for research in Epidemiology and Population Health, U1018, Respiratory and Environmental Epidemiology Team and Université Paris Sud 11, UMRS 1018, Villejuif, France), F. Demenais (genetics; Inserm U946, France) and I. Pin (clinical aspects; Inserm, U823, Centre de Recherche Albert Bonniot, La Tronche, Université Joseph Fourier, and CHU, Grenoble, France). Respiratory epidemiology: M. Korobaeff (EGEA1) and F. Neukirch (EGEA1) (both Inserm U700, Paris), I. AnnesiMaesano (Inserm 707, Paris), F. Kauffmann, N. Le Moual, R. Nadif and M.P. Oryszczyn (all Inserm CESP/U1018), and V. Siroux (Inserm U823, Grenoble). Genetics: J. Feingold (Inserm U 393, Paris), E. Bouzigon, F. Demenais and M.H. Dizier (all Inserm U946), and I. Gut and M. Lathrop (both CNG, Evry, France). The EGEA clinical centres in France were as follows. Grenoble: I. Pin and C. Pison; Lyon: D. Ecochard (EGEA1), F. Gormand and Y. Pacheco; Marseille: D. Charpin (EGEA1) and D. Vervloet; Montpellier: J. Bousquet; Paris Cochin: A. Lockhart (EGEA1) and R. Matran (now in Lille); Paris Necker: E. Paty and P. Scheinmann; Paris Trousseau: A. Grimfeld, J. Just. Data and quality management was performed by the following individuals: J. Hochez (EGEA1; Inserm ex-U155), N. Le Moual (Inserm CESP/U 1018), C. Ravault (Inserm ex-U780), N. Chateigner (Inserm ex-U794), and J. Ferran (Grenoble).

The authors thank all those who participated in the setting of the study and on the various aspects of the examinations involved: interviewers, technicians for lung function testing and skin-prick tests, blood sampling, immunoglobulin E determinations, coders, those involved in quality control, data and sample management, and all those who supervised the study in all centres. The authors are grateful to the three CIC-Inserm of Necker, Grenoble and Marseille, who supported the study and in which subjects were examined. They thank G. Vasseur (Inserm U780, Villejuif, France) for job coding. They are indebted to all the individuals who participated without whom the study would not have been possible.

\section{REFERENCES}

1 Toren K, Blanc PD. Asthma caused by occupational exposures is common - a systematic analysis of estimates of the populationattributable fraction. BMC Pulm Med 2009; 9: 7.

2 Kogevinas M, Zock JP, Jarvis D, et al. Exposure to substances in the workplace and new-onset asthma: an international prospective population-based study (ECRHS-II). Lancet 2007; 370: 336-341.

3 Henneberger PK. Work-exacerbated asthma. Curr Opin Allergy Clin Immunol 2007; 7: 146-151.

4 Tarlo SM, Balmes J, Balkissoon R, et al. Diagnosis and management of work-related asthma: American College Of Chest Physicians Consensus Statement. Chest 2008; 134: 1S-41S.

5 Le Moual N, Kauffmann F, Eisen EA, et al. The healthy worker effect in asthma: work may cause asthma, but asthma may also influence work. Am J Respir Crit Care Med 2008; 177: 4-10.

6 Olivieri M, Mirabelli MC, Plana E, et al. Healthy hire effect, job selection and inhalation exposure among young adults with asthma. Eur Respir J 2010; 36: 517-523.

7 Radon K, Huemmer S, Dressel H, et al. Do respiratory symptoms predict job choices in teenagers? Eur Respir J 2006; 27: 774-778.

8 Kauffmann F, Dizier MH, Pin I, et al. Epidemiological study of the genetics and environment of asthma, bronchial hyperresponsiveness, and atopy: phenotype issues. Am J Respir Crit Care Med 1997; 156: S123-S129.

9 Ferris BG. Epidemiology Standardization Project (American Thoracic Society). Am Rev Respir Dis 1978; 118: 1-120.

10 Siroux V, Oryszczyn MP, Paty E, et al. Relationships of allergic sensitization, total immunoglobulin $\mathrm{E}$ and blood eosinophils to asthma severity in children of the EGEA Study. Clin Exp Allergy 2003; 33: 746-751.
11 National Heart, Lung, and Blood Institute. Global strategy for asthma management and prevention. http://www.ginasthma. org/GuidelineItem.asp?intId $=82$ Date last accessed: 9 April 2010. Date last updated: 2002.

12 Bouzigon E, Siroux V, Dizier MH, et al. Scores of asthma and asthma severity reveal new regions of linkage in EGEA study families. Eur Respir J 2007; 30: 253-259.

13 Pekkanen J, Sunyer J, Antó JM, et al. Operational definitions of asthma in studies on its aetiology. Eur Respir J 2005; 26: 28-35.

14 Sunyer J, Pekkanen J, Garcia-Esteban R, et al. Asthma score: predictive ability and risk factors. Allergy 2007; 62: 142-148.

15 Rage E, Siroux V, Le Moual N, et al. Are asymptomatic airway hyperresponsiveness and allergy risk factors for asthma? A longitudinal study. Eur Respir J 2009; 33: 218-219.

16 Chinn S, Burney P, Sunyer J, et al. Sensitization to individual allergens and bronchial responsiveness in the ECRHS. European Community Respiratory Health Survey. Eur Respir J 1999; 14: 876-884.

17 International Labour Office. International standard classification of occupations, revised Edn. Geneva, International Labour Office, 1988.

18 Kennedy SM, Le Moual N, Choudat D, et al. Development of an asthma specific job exposure matrix and its application in the epidemiological study of genetics and environment in asthma (EGEA). Occup Environ Med 2000; 57: 635-641.

19 Matheson MC, Benke G, Raven J, et al. Biological dust exposure in the workplace is a risk factor for chronic obstructive pulmonary disease. Thorax 2005; 60: 645-651.

20 Sunyer J, Kogevinas M, Kromhout $\mathrm{H}$, et al. Pulmonary ventilatory defects and occupational exposures in a population-based study in Spain. Spanish Group of the European Community Respiratory Health Survey. Am J Respir Crit Care Med 1998; 157: 512-517.

21 Iwatsubo Y, Matrat M, Brochard P, et al. Healthy worker effect and changes in respiratory symptoms and lung function in hairdressing apprentices. Occup Environ Med 2003; 60: 831-840.

22 Monso E, Malo JL, Infante-Rivard C, et al. Individual characteristics and quitting in apprentices exposed to high-molecularweight agents. Am J Respir Crit Care Med 2000; 161: 1508-1512.

23 de Vocht F, Zock JP, Kromhout H, et al. Comparison of selfreported occupational exposure with a job exposure matrix in an international community-based study on asthma. Am J Ind Med 2005; 47: 434-442.

24 Thaon I, Wild P, Mouchot L, et al. Long-term occupational consequences of asthma in a large French cohort of male workers followed up for 5 years. Am J Ind Med 2008; 51: 317-323.

25 Blanc PD, Jones M, Besson C, et al. Work disability among adults with asthma. Chest 1993; 104: 1371-1377.

26 Pin I, Siroux V, Cans C, et al. Familial resemblance of asthma severity in the EGEA study. Am J Respir Crit Care Med 2002; 165: 185-189.

27 Wiebert P, Svartengren M, Lindberg M, et al. Mortality, morbidity and occupational exposure to airway-irritating agents among men with a respiratory diagnosis in adolescence. Occup Environ Med 2008; 65: 120-125.

28 Chen R, Seaton A. The influence of study characteristics on the healthy worker effect: a multiple regression analysis. Occup Med (Lond) 1996; 46: 345-350.

29 Marabini A, Dimich-Ward H, Kwan SY, et al. Clinical and socioeconomic features of subjects with red cedar asthma. A follow-up study. Chest 1993; 104: 821-824.

30 Bhinder S, Cicutto L, Abdel-Qadir HM, et al. Perception of asthma as a factor in career choice among young adults with asthma. Can Respir J 2009; 16: e69-e75.

31 Vandenplas O, Henneberger PK. Socioeconomic outcomes in work-exacerbated asthma. Curr Opin Allergy Clin Immunol 2007; 7: 236-241.

32 Vandenplas O, Toren K, Blanc PD. Health and socioeconomic impact of work-related asthma. Eur Respir J 2003; 22: 689-697. 